\title{
Whole Cell Recordings from Acutely Dissociated Septal Neurons
}

\author{
MASASHI TSURUSAKI, HIROSHI HASUO AND TAKASHI AKASU \\ Department of Physiology, Kurume University School of Medicine, \\ Kurume, 830 Japan
}

Received for publication March 24, 1990

\begin{abstract}
Key words: whole cell recording-dissociated cell - septal neuron - adult rat - membrane properties
\end{abstract}

Electrophysiological studies have been performed on cultured neurons isolated from the fetal (or newborn) rat or mouse central nervous system (CNS) (Barker and Ransom, 1978a, $b$; Mathers and Barker, 1980). Recently, several reports have appeared describing the electrophysiological properties of acutely dissociated neurons from the adult mammalian CNS (Kay and Wong, 1986; Kiskin et al. 1986 $a, b$; Akaike and Kaneda, 1989). In this study, single neurons were isolated from the dorsolateral region of the rat septal slice preparation. Resting and action potentials of acutely dissociated septal neurons had characteristics similar to the potentials in intact neurons in septal slice preparations.

Adult (2-4 weeks) male Wister rats, weighing $100-150 \mathrm{~g}$, were decapitated and the brain including the septal regions was rapidly sliced at a thickness of $500 \mu \mathrm{m}$ (Stevens et al. 1984). The slices were maintained in an oxygenated artificial cerebrospinal fluid (A-CSF) of the following composition (mM): $\mathrm{NaCl}, 117 ; \mathrm{KCl}, 4.7$; $\mathrm{CaCl}_{2}$ ， 2.5; $\mathrm{MgCl}_{2}$, $1.2 ; \mathrm{NaH}_{2} \mathrm{PO}_{4}, 1.6$; $\mathrm{NaHCO}_{3}, 25$ and glucose, 10. After incubation of the slices for $30-40 \mathrm{~min}$ in A-CSF at room temperature, the slices were en- zymatically treated in A-CSF containing $0.05 \%$ collagenase and $0.1 \%$ trypsin (type XI) bubbled with $95 \% \mathrm{O}_{2}, 5 \% \mathrm{CO}_{2}$ at $37^{\circ} \mathrm{C}$ for $60-90 \mathrm{~min}$. The enzyme treatment was halted by washing with A-CSF twice, the slices were then placed in a glass Petri dish filled with A-CSF, and the septal regions were manually removed from the slice using a blade. The isolated regions were cut with a blade into fragments of about $3 \mathrm{~mm}$ square. The fragments were placed in small plastic tubes filled with L-15 culture medium (incubation solution) with $20 \%$ fetal bovine serum. They were separated by gentle pipetting, a few times, with a large orifice pipette; then they were dissociated into small clusters of neurons by gentle pipetting with a fire-polished pipette of $500 \mu \mathrm{m}$, tip diameter. Clusters of neurons were triturated to isolate the cells using a fine pipette of $100-200 \mu \mathrm{m}$ tip diameter. The isolated neurons were maintained in the incubation solution without gas bubbling. Neurons from the septal region were isolated and preserved in an incubation solution, and were photographed with an inverted microscope.

Reprint requests to: Dr. M. Tsurusaki.

Department of Physiology, Kurume University School of Medicine, 67 Asahi-machi, Kurume, 830 Japan 

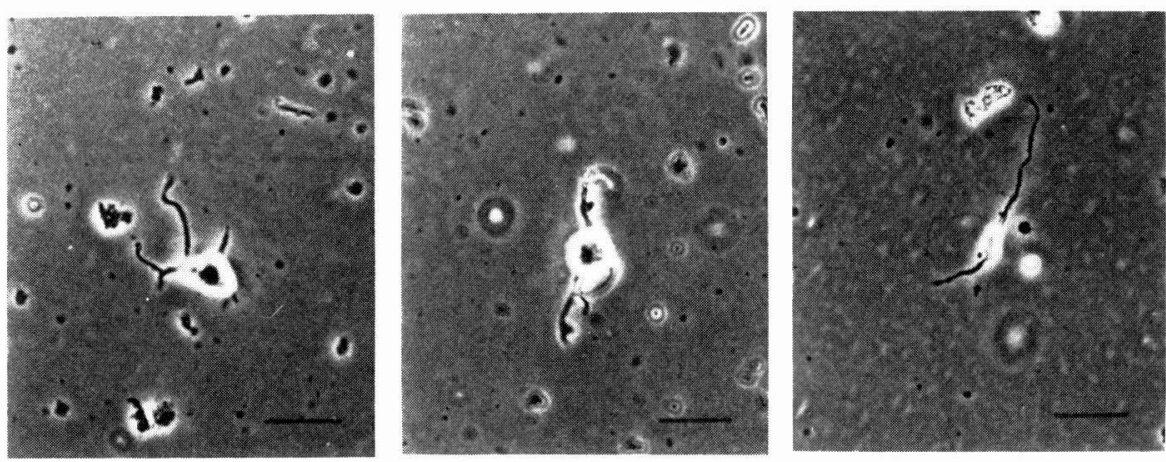

Plate 1. Isolated septal neurons with dendrites. Each bar represents $20 \mu \mathrm{m}$.

The isolated septal cells were spindle, bipolar or multipolar shaped with a phasebright smooth surface. The internal structures such as the nuclear membrane, nucleolus, endoplasmic reticulum, etc. were transparent (Plate 1). Some of these neurons possessed a few dendrites. Whole cell recordings were made from these acutely dissociated septal neurons. Patch pipettes were filled with an internal solution of the following composition $(\mathrm{mM})$; $\mathrm{KF}, 100 ; \mathrm{KCl}, 30$ and $\mathrm{ATP}-\mathrm{Mg}, 1$ (Kaneda et al. 1988). The tip resistances of the pipettes were $5-10 \mathrm{M} \Omega$. A slight positive pressure was applied to the patch pipette before suctioning the neuron. After placing the tip close to the surface of a neuron, removal of the positive pressure induced the cell to adhere to the pipette, and a giga-ohm seal was formed within 3 min. Fig. 1 shows an example of a whole cell recording from an acutely dissociated septal neuron. The membrane potential and resistance at the resting potential were $-63--83 \mathrm{mV}(\mathbf{n}=5)$ and $54-70 \mathrm{M} \Omega$ $(\mathrm{n}=5)$.

Enzymatic treatment was one of the most important steps for the successful isolation of the septal neurons from an adult rat preparation, i. e. the type of enzyme used and the duration of the enzyme treatment. In this study, we used trypsin type $\mathrm{XI}(248 \mathrm{U} / \mathrm{ml})$ was applied for

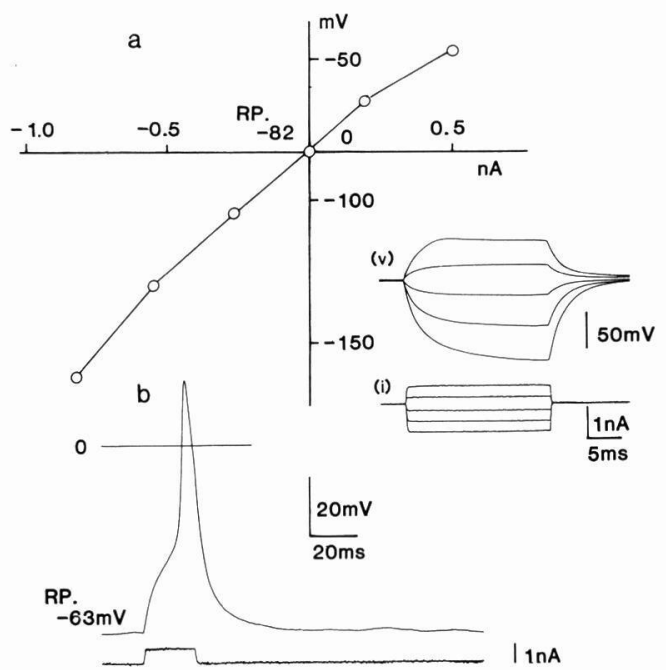

Fig. 1. An action potential recorded from an acutely dissociated septal neuron.

60-90 min to septal slices, as has been reported for other preparations (Okun, 1972; Kay and Wong, 1986; Mattson and Kater, 1988; Yakel et al. 1988; Delree et al. 1989). The membrane toxicity of trypsin type XI seemed to be negligible, because (1) the configuration of the isolated neurons was comparable to that of CNS neurons of a fetal or neonatal preparation isolated without using trypsin, and (2) the electrophysiological properties of the isolated 
septal neurons were similar to those of intact neurons in septal slices (Stevens et al. 1984). However, the repolarization of the action potential was somewhat slower than in intact neurons of septal slices. Improved techniques may be needed to isolate healthy septal neurons from adult rat brains.

Acknowledgments: This work was supported by a Grant-in-Aid for Scientific Research from the Ministry of Education, Science and Culture of Japan.

\section{References}

Akaike, N. and Kaneda, M. (1989). Glycinegated chloride current in acutely isolated rat hypothalamic neurons. J. Neurophysiol. 62, 1400-1409.

BarkeR, J. L. and RAnsom, B.R. (1978a). Amino acid pharmacology of mammalian central neurones grown in tissue culture. J. Physiol. (Lond.) 280, 331-354.

Barker, J. L. and Ransom, B. R. (1978b). Pentobarbitone pharmacology of mammalian central neurones grown in tissue culture. J. Physiol. (Lond.) 280, 355-372.

Delree, P., Leprince, P., Schoenen, J. and Moonen, G. (1989). Purification and culture of adult rat dorsal root ganglia neurons. J. Neurosci. Res. 23, 198-206.

Kaneda, M., Nakamura, H. and Akaike, N. (1988). Mechanical and enzymatic isolation of mam- malian CNS neurons. Neurosci. Res. 5, 299315.

KAY, A.R. and Wong, R.K.S. (1986). Isolation of neurons suitable for patch-clamping from adult mammalian central nervous systems. J. Neurosci. Meth. 16, 227-238.

Kiskin, N. I., Krishtal, O. A. and Tsyndrenko, A. YA. (1986a). Excitatory amino acid receptors in hippocampal neurons: kainate fails to desensitize them. Neurosci. Lett. 63, 225-230.

Kiskin, N. I., Krishtal, O. A., Tsyndrenko, A. YA. and Akaike, N. (1986b). Are sulfhydryl groups essential for function of the glutamate-operated receptor-ionophore complex? Neurosci. Lett. 66, 305-310.

Mathers, D. A. and Barker, J. L. (1980). (-) Pentobarbital opens ion channels of long duration in cultured mouse spinal neurons. Science 209, 507-509.

Mattson, M.P. and Kater, S. B. (1988). Isolated hippocampal neurons in cryopreserved longterm cultures: Development of neuroarchitecture and sensitivity to NMDA. Int. J. Devl. Neurosci. 6, 439-452.

Оким, L. M. (1972). Isolated dorsal root ganglion neurons in culture: Cytological maturation and extension of electrically active processes. J. Neurobiol. 3, 111-151.

Stevens, D. R., Gallagher, J. P. and ShinnickGALLAGHER, P. (1984). Intracellular recordings from rat dorsolateral septal neurons, in vitro. Brain Res. 305, 353-356.

YAKel, J. L., TRUSSELl, L.O. and JACKSON, M.B. (1988). Three serotonin responses in cultured mouse hippocampal and striatal neurons. J. Neurosci. 8, 1273-1285. 